\title{
Outbreak of acute fasciolosis in sheep farms in a Mediterranean area arising as a possible consequence of climate change
}

\author{
Antonio Bosco ${ }^{1}$, Laura Rinaldi ${ }^{1,3}$, Vincenzo Musella ${ }^{2}$, Alessandra Amadesi ${ }^{1}$, Giuseppe \\ Cringoli ${ }^{1,3}$ \\ ${ }^{1}$ Department of Veterinary Medicine and Animal Productions, University of Naples Federico II, Naples, Italy \\ and CREMOPAR Campania Region, Naples, Italy; ${ }^{2}$ Department of Health Sciences, University "Magna \\ Grocia" of Catanzaro, Catanzaro, Italy; ${ }^{3}$ Interdipartimental Centre of Research in Parasitology-CIRPAR, \\ Naples, Italy
}

\begin{abstract}
The objective of the present study was to investigate whether climate change in recent years have influenced the onset of acute outbreaks of Fasciola hepatica in ovine farms in southern Italy. In May-June 2014, a severe outbreak of F. hepatica occurred in three sheep farms in the Campania region. Clinical, coprological and necroscopic examinations were performed. Morbidity and mortality due to F. hepatica were 3-67\% and 3-50\%, respectively. Coprological examinations showed high values of $F$. hepatica eggs per gram (EPG) of faeces (860-1,240). Similarly, high adult parasitic burdens were found in animals that had sucombed (124-426 flukes). The study area was georeferenced and climatic data (temperature, humidity, days of rain and total amount of rainfall) were recorded at four georeferenced meterological stations in the study area. Montly data were processed and analyzed for the period 2000-2013 to evaluate the change of the climatic parameters during these years. The results show that there was a significant increase $(\mathrm{P}<0.001)$ of temperature, increased rainfall and increase in the number of rainy days compared to previous years. In addition to the outbreak reported here, we discuss the potential effects of climate change on the epidemiology of F. bepatica and the implications for sheep farming in the Mediterranean area.
\end{abstract}

Keywords: acute fasciolosis, sheep, climate change, geographical information systems, Italy.

\section{Introduction}

The liver fluke Fasciola hepatica is a trematode parasite with an economic impact on livestock in most regions of the world (Charlier et al., 2014). It presents the widest latitudinal, longitudinal and altitudinal distribution known at present (Mas-Coma et al., 2009; Afshan et al., 2014). All grazing animals are exposed to $F$. hepatica infections at pasture where the climate supports its transmission, so any future intensification of livestock farming would also increase the risk of infection/disease. Liver fluke infection ranks as one of the top causes of lost productivity in small and large ruminants by the recent DISCONTOOLS programme (http://www.discontools.eu/home/index), which reinforces the increasing worry regarding the impact of

\section{Corresponding author:}

Laura Rinaldi

Unit of Parasitology and Parasitic Diseases

Department of Veterinary Medicine and Animal Productions

University of Naples Federico II

Via della Veterinaria 1, 80137 Naples, Italy

Tel/Fax +39 $081253-6283$

E-mail: lrinaldi@unina.it
F. hepatica upon animal health, welfare and productivity in the European Union (EU) (Charlier et al., 2014; Rinaldi and Cringoli, 2014). F. hepatica represents also a public health problem, since the parasite is endemic in many parts of the world from South America and Middle East to eastern Europe with up to 2.4 million people infected and approximately 180 million at risk (Mas-Coma et al., 2014).

The spread of F. hepatica is associated with the presence of Galba truncatula snails, which serve as the intermediate hosts. It is unclear what triggers outbreaks of clinical fasciolosis in ruminants. It has been suggested that the change in environmental conditions due to climate change is the reason for the current widespread occurrence of fasciolosis (Kenyon et al., 2009; Van Dijk et al., 2010). Rapsch et al. (2008) mention that the distribution of the free-living stages and the intermediate molluscan host, G. truncatula depend on a range of climatic factors, particularly temperature and rainfall, that also affect the survival of F. hepatica eggs and metacercarie. Therefore, climatic factors are seen as sensitive means for forecasting annual F. hepatica prevalence and the geospatial variability of the liver fluke (Lopez et al., 2012; 
Caminade et al., 2015; Ducheyne et al., 2015). Prediction of infection risk can be used to increase awareness of the possible economic impact on husbandry and allow the organisation of animal health control programmes (Bennema et al., 2010). For the development of such prediction system, knowledge of the epidemiology and spatio-temporal distribution of F. hepatica is required.

F. hepatica has a low prevalence $(1-12.4 \%)$ in sheep farms of southern Italy as demonstrated by cross-sectional surveys conducted in various regions in recent years (Cringoli et al., 2002; Musella et al., 2011; Bosco et al., 2013) using geographic information systems (GIS) to plan sampling protocols, risk mapping and performing ecological analyses (Cringoli et al., 2002; Musella et al., 2014). These studies show a clustered distribution of $F$. hepatica and the main risk factors associated with the presence of fasciolosis was found to be the presence of large pastures with impermeable soil (Cringoli et al., 2002; Musella et al., 2011). In southern Italy, as in other regions, infection levels and incidence of disease due to liver fluke depend very much on rainfall during the period from late spring to late summer, when many fluke eggs hatch and snails multiply, as well as in the autumn when cercariae develop and are released on wet pastures before encysting onto herbage (Taylor, 2012).

In this paper, a severe outbreak of acute fasciolosis is reported in three sheep farms in a Mediterranean area of southern Italy, where a progressive increase of precipitation was registered in recent years. We report clinical, coprological and necroscopic findings associated with climate changes in this region. The final aim of the present study was to investigate whether climate change in recent years have influenced the onset of acute outbreaks of F. hepatica in ovine farms of southern Italy.

\section{Material and methods}

\section{Study area}

The F. hepatica outbreak occurred in sheep bred in Salerno Province (latitude 40 33' 30", longitude $\left.15^{\circ} 04^{\prime} 17^{\prime \prime}\right)$ in the Campania region of southern Italy (Fig. 1). Montly data were processed and analyzed for the period 2000-2013.

The climate in this area is characterized by: dry summers and rainy autumns and winters. The overall pasture type of the three farms, where the outbreak occurred, was 320 ha of small, hilly plain located about $12 \mathrm{~km}$ from the Tyrrhenian Sea, roughly $50 \mathrm{~m}$ above sea level. It was a natural pasture with shrubs along a brook cossing the area and on the riverbanks that fomed its borders. The predominant forage species were wild Galium spp., Cichorium spp., Dactylis glomerata and Lolium perenne. The soil had a clay surface layer. Wherever there were surface lower areas, subsidences, this layer accumulated water from autumn to early summer. G. truncatula, the intermediate host of F. hepatica, was found both in these subsidences and along the banks of the brook and the river.

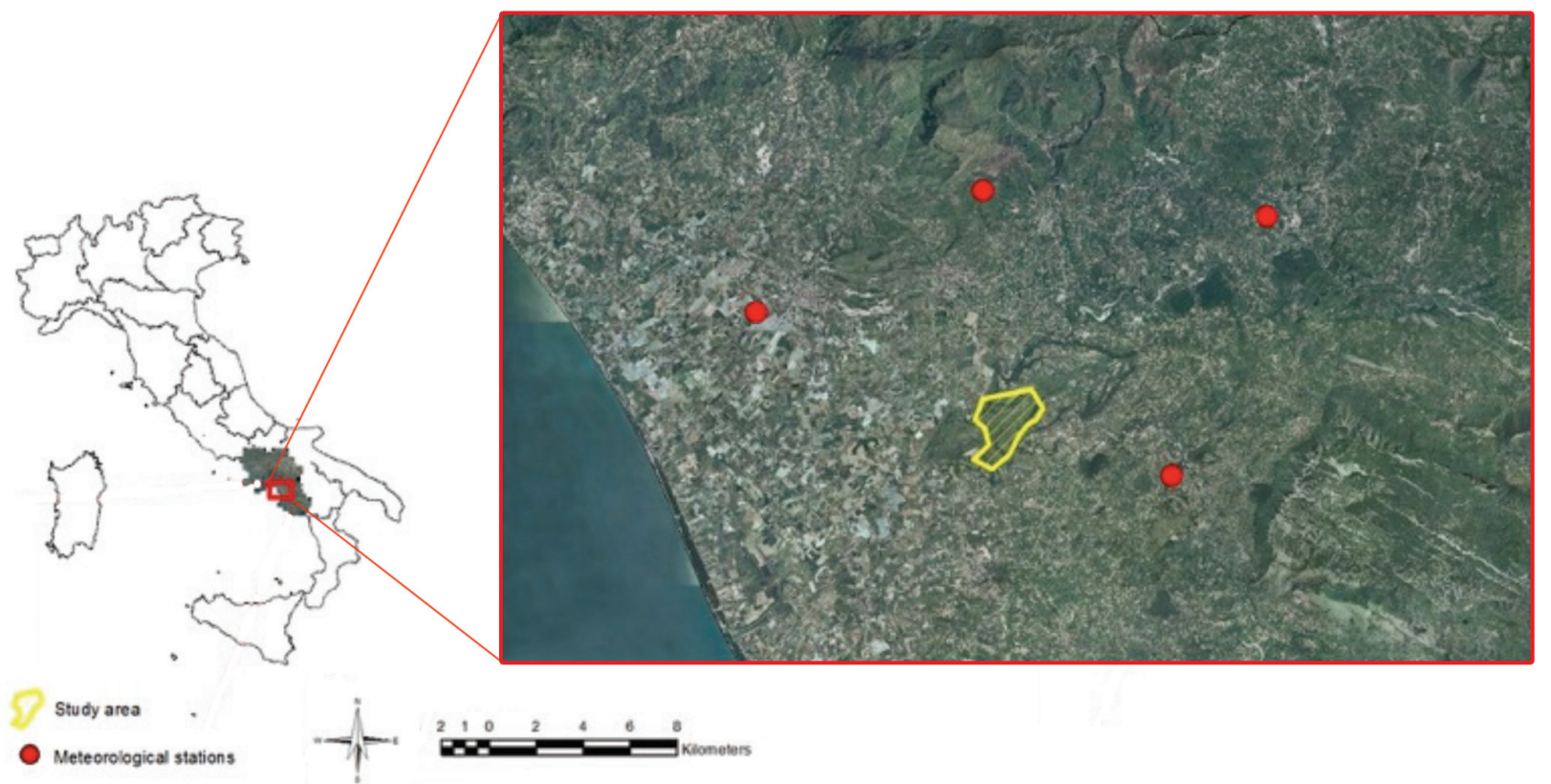

Fig. 1. Study area including the localization of meteorological stations. 


\section{Climatic data}

Climatic data were obtained from four meteorological stations in proximity of the area, where the outbreak occurred (Fig. 1). Daily data (minimum, maximum, mean and quartiles) of temperatures, humidity, rainfall (in $\mathrm{mm}$ ) and numbers of rainy days were recorded, processed and analyzed from 2000 to 2013 to evaluate the possible climate changes during the years in the study area. For each parameter, data were divided into three periods: first (I) period (from 2000 to 2005), second (II) period (from 2006 to 2009) and third (III) period (from 2010 to 2013). Statistical analysis on climate data for differences among years and periods were analyzed using a one-way ANOVA with post hoc Fisher's least significant difference (LSD). Statistical analysis was carried out using STATA 10.0 software (StataCorp, TX, USA).

\section{F. hepatica outbreak}

The three farms of the study area were composed of approximately 300-700 mixed-breed dairy sheep pasturing all year long. All sheep were raised on the farms with parturition concentrated in the months of February and October, so lactating animals were always present throughout the year. These farms had a known history of fasciolosis; however, strategic schemes of anthelmintic treatments (albendazole, twice a year) successfully reduced both the prevalence and intensity of F. hepatica to a level, at which there were no longer any clinical symptoms of the disease until the spring of 2014. Fecal examinations and necropsies performed in previous years on the farms showed low prevalence rates of $F$. hepatica (1-5\%).

In May 2014, the farmers observed the first suspected cases of acute fasciolosis. The animals on the farms were monitored clinically and coprologically for four months (from May to August 2014) and during this period necropsies were also performed on dead sheep.

\section{Clinical and laboratory examination}

All sheep of the flocks were subjected to clinical examination on a monthly basis during the observation period. Clinical signs included weight loss, mucosal pallor, submandibular edema, ascites, apathy, depression and muscle tremors. In many sheep, severe fasciolosis was followed by sudden death in a short time.

In each farm, faecal samples were collected from 50 ewes at monthly intervals. Individual faecal egg counts were carried out by the FLOTAC Basic Technique (Cringoli et al., 2010), with an analytic sensitivity of 1 egg per gram (EPG) of faeces, using zinc sulfate (specific gravity $=1.350$ ) as flotation solution (Cringoli et al., 2010; Duthaler et al., 2010).

All animals found dead during the study period were subjected to necroscopic examination. Livers were removed and transferred to the laboratory in thermal containers. F. hepatica flukes were collected from the gall bladder and excised bile ducts to be counted. Two/three samples of the liver were taken from the sheep, fixed in $10 \%$ neutral buffered formalin and routinely processed for histological examination.

\section{Results}

\section{Clinical and laboratory outcome}

During the observation period, the morbidity due to fasciolosis in the three farms ranged from 3 to $67 \%$ and mortality from 3 to $50 \%$, respectively. The results of coprological examinations showed high values of F. hepatica EPG $(860$ to 1,240) in the sheep (Table 1).

Table 1. Monthly prevalence, EPG (mean \pm standard deviation and range) of F. hepatica in the three sheep farms during the outbreak.

\begin{tabular}{|c|c|c|c|c|c|c|}
\hline \multirow{2}{*}{$\begin{array}{l}\text { Month } \\
\text { Farm }\end{array}$} & \multicolumn{3}{|c|}{ May } & \multicolumn{3}{|c|}{ June } \\
\hline & Prevalence $(\%)$ & EPG Mean \pm SD & EPG range & Prevalence $(\%)$ & EPG Mean \pm SD & EPG range \\
\hline 1 & 81 & $860 \pm 64.4$ & $125-1234$ & 84 & $920 \pm 321.3$ & $108-1004$ \\
\hline 2 & 92 & $1232 \pm 213.5$ & $232-1452$ & 90 & $1130 \pm 211.1$ & $322-1231$ \\
\hline 3 & 94 & $1124 \pm 235.3$ & $198-1326$ & 95 & $1212 \pm 216.4$ & $373-1321$ \\
\hline Month & \multicolumn{3}{|c|}{ July } & \multicolumn{3}{|c|}{ August } \\
\hline Farm & Prevalence $(\%)$ & EPG Mean \pm SD & EPG range & Prevalence $(\%)$ & EPG Mean \pm SD & EPG range \\
\hline 1 & 82 & $882 \pm 352.5$ & $82-1124$ & 83 & $1005 \pm 341.9$ & $102-1132$ \\
\hline 2 & 89 & $1081 \pm 231.6$ & $221-1236$ & 90 & $1210 \pm 312.9$ & $230-1245$ \\
\hline 3 & 92 & $1135 \pm 245.7$ & $321-1435$ & 92 & $1240 \pm 231.8$ & $243-1348$ \\
\hline
\end{tabular}




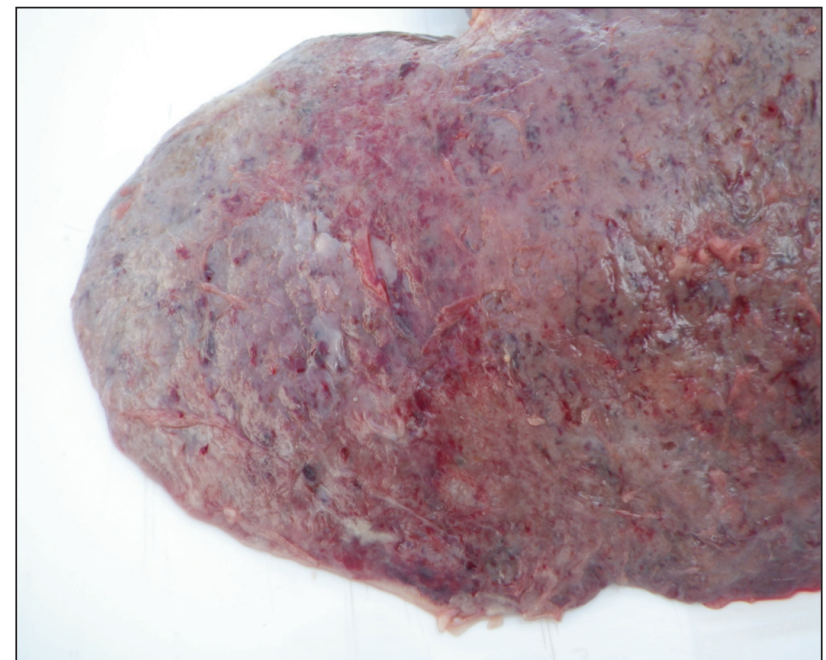

Fig. 2. Hepatic lobe of a sheep that died during the study period with severe lesions caused by the migration of Fasciola hepatica flukes.

A total of 30 sheep died during the study period. Gross pathological changes with varying severity, as ascites, submandibular edema, hepatic fibrosis with a high number of F. hepatica in bile ducts, were observed in all these animals. The liver surface was slightly irregular and covered by fibrinous exudates, dark red areas of hemorrhage and fibrin deposition. Irregular fibrosis was found to extend from the capsule into the parenchyma with prominent bile ducts and multifocal abscessation. Focal pale areas of more discrete fibrosis were evident within the parenchyma.
In addition different sheep showed focal abscesses, portal-portal bridging fibrosis and chronic active periportal inflammation (Fig. 2).

Histology confirmed that large areas of the liver had been destroyed by the presence of areas of necrosis. These areas contained large numbers of degenerate neutrophils and eosinophils and were surrounded by activated macrophages and occasional giant cells. Remnants of parasites were seen in the centre of some of these necrotic areas. Other areas showed fibrosis with irregular bands dissecting residual hepatocytes with a mixed inflammatory component of neutrophils, eosinophils and macrophages. The bile duct epithelium was frequently hyperproliferative and there were areas of biliary reduplication.

\section{Climatic data}

Climatic data collected from 2000 to 2013 showed specific trends for each parameter investigated (Fig. 3). Temperature data showed a trend with a low temperature in the first period (mean temperature $=13.4^{\circ} \mathrm{C}$ ) and high temperatures during the second (mean temperature $=18.8^{\circ} \mathrm{C}$ ) and the third period (mean temperature $\left.=14.6^{\circ} \mathrm{C}\right)$. Total amounts of rain $(\mathrm{mm})$ and number of days per month showed a trend with high values in the first period (mean $=65.4 \mathrm{~mm} ; 10.4$ days) and the third period (mean $=99.0 \mathrm{~mm} ; 11.6$ days). Humidity remained constant during all periods of the study.
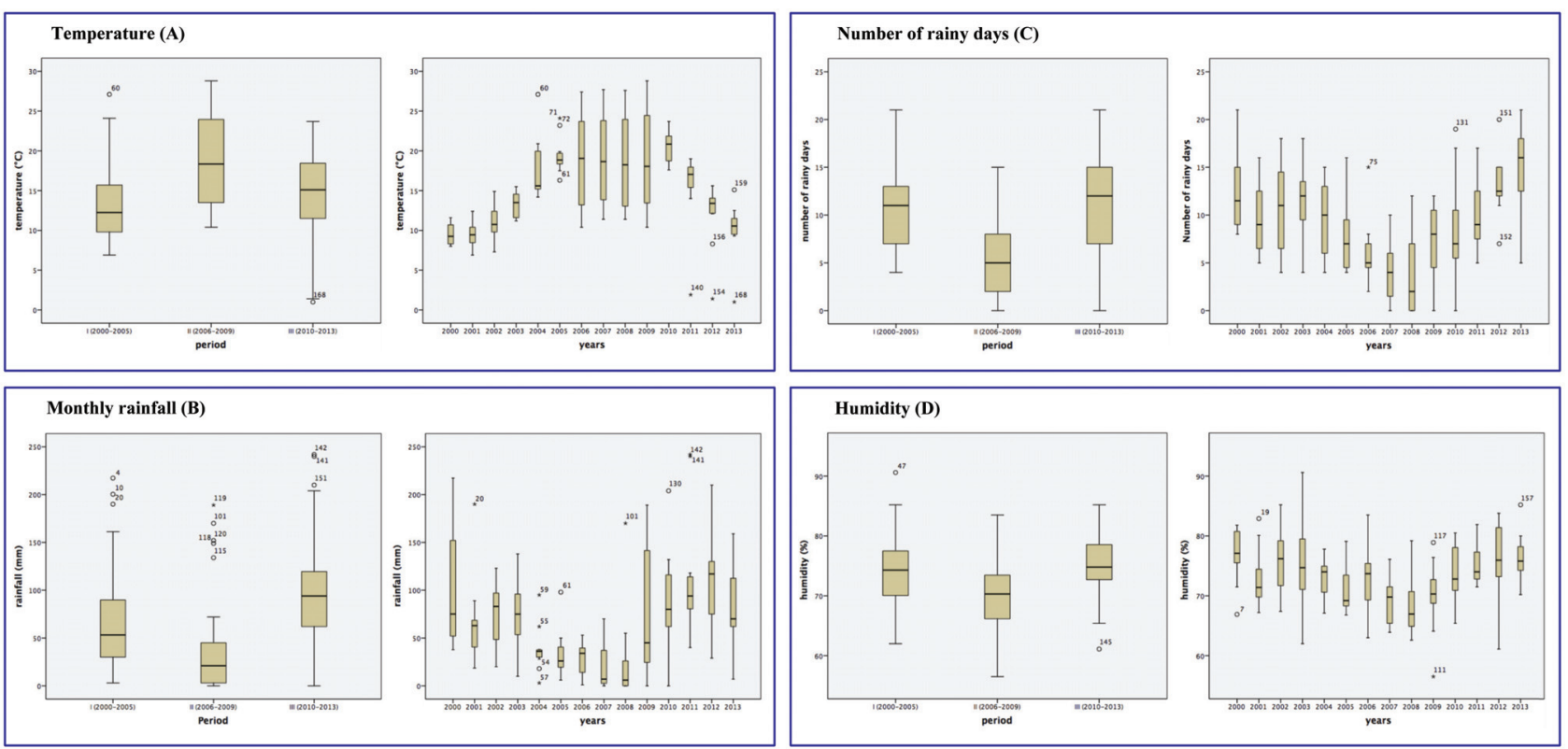

Fig. 3. Box plots showing data blocks (temperature, rainfall, number of rainy days and humidity) collected in periods I, II and III each study year (2000 to 2013). 
Temperature data showed a strong significative difference between the first and second period $\left(+5.5^{\circ} \mathrm{C}\right.$, $\mathrm{P}<0.001)$ and between the second and third period $\left(+4.2{ }^{\circ} \mathrm{C}, \mathrm{P}<0.001\right)$. Precipitation data ( $\mathrm{mm}$ of rain) showed a significant difference between the first and second period $(-27.5 \mathrm{~mm}, \mathrm{P}<0.05)$, between the second and third period $(+61.1 \mathrm{~mm}, \mathrm{P}<0.001)$ and between the first and third period $(+33.6 \mathrm{~mm}$, $\mathrm{P}<0.05)$. Days of rain data showed a strong significant difference between the second and third period (-5.1 days, $\mathrm{P}<0.001)$, whereas there was not a significant difference between the first and third period.

\section{Discussion}

The outbreak of fasciolosis described in this paper demonstrates changes in the epidemiology of F. hepat$i c a$ in sheep from what is conventionally reported in southern Italy, where these infections are usually clustered in a few concentrated zones and usually subclinical (Cringoli et al., 2002; Musella et al., 2011). The current outbreak was characterized by a severe acute infection by $F$. hepatica with mortality rates as high as $50 \%$, which is in agreement with other studies (Fiss et al., 2013). This case had clear economic consequences (data not shown), suggesting that alterations in the epidemiology of F. hepatica resulting from climate change will influence the profitability of sheep farmers in southern Italy and probably also in other regions in the Mediterranean area.

It seems clear that the outbreak of fasciolosis was related to changes in climate in the study area over the study period (2000-2013) that showed significant changes in temperature, rainfall and number of rainy days, in particular in the latest years (2010-2013). A higher number of rainy days, as well as absolute amount of rainfall, compared to earlier periods was observed, which likely reflects a wider distribution of humid areas (e.g. small water bodies) in the pastures. The life cycle of $F$. hepatica contains several stages that could potentially be affected by changing the abovementioned climatic parameters. For example, moisture is required for the free-living miracidial and cercarial stages. G. truncatula snails are generally found in permanently humid areas, but can spread into any wet area, such as flooded areas, drainage channels and other small water bodies. Interestingly, small water bodies, such as ponds, ditches and wet areas (particularly those containing animal footprints), were mapped at an extraordinary fine scale using very high resolution imagery and identified as suitable habitats for G. truncatula at the farm level in Belgium (De
Roeck et al., 2014).

It is now widely accepted that climate change is happening, and that it represents one of the greatest threats faced by our planet, its populations and economies (Skuce et al., 2013). According to the United Nations Intergovernmental Panel on Climate Change (IPCC), average global temperatures will increase between $1.8^{\circ} \mathrm{C}$ and $4.0^{\circ} \mathrm{C}$ in the next 90 years (Yatoo et al., 2012). Our findings demonstrate clear signs of climate change in southern Italy in the short period of 14 years and that the distribution of fasciolosis is responding to it.

Climate change is a driving force for livestock parasite risk. Levels and seasonal patterns of parasite challenge to livestock are likely to be affected by climate change, through direct effects on life cycle stages and intermediate host outside the definitive host (Morgan and Van Dijk, 2012). Our results represent a small-scale validation of the prediction model developed by Caminade et al. (2015) at the European level. In southern Europe, altough the simulated burden of fasciolosis is low, projected climate change will affect winter transmission and support the development of the free-living and the intra-molluscan stages (Caminade et al., 2015). The findings of the present study confirm that liver flukes present an increasing, already serious risk to the health, welfare and productivity of sheep, goat and cattle potentially compromising Europe's food security (Caminade et al., 2015).

This climate-related, increased F. hepatica challenge could lead to the more frequent use of flukicides for disease control, which could further select for the development of anthelmintic resistance and compound the production-limiting effects of the disease. Effective monitoring, including active surveillance of disease outbreaks, is required in order to develop suitable control strategies and to model recent and future risk of F. hepatica infection in livestock in southern Italy and beyond. We also need an improved understanding of parasite population genetics and the phenotypic and genotypic basis of adaptation to a changing climate. All of this knowledge would help the development of sustainable, effective control regimes that farmers can use in order to maintain animal health, welfare and productivity.

\section{Acknowledgements}

The research leading to these results has received funding from the European Union Seventh Framework Programme FP7KBBE-2011-5 under grant agreement no. 288975. 


\section{References}

Afshan K, Fortes-Lima CA, Artigas P, Valero AM, Qayyum M, Mas-Coma S, 2014. Impact of climate change and man-made irrigation systems on the transmission risk, long-term trend and seasonality of human and animal fascioliasis in Pakistan. Geospat Health 8, 317-334.

Bennema SC, Ducheyne E, Vercruysse J, Claerebout E, Hendrickx G, Charlier J, 2010. Relative importance of management, meteorological and environmental factors in the spatial distribution of Fasciola hepatica in dairy cattle in a temperate climate zone. Int J Parasitol 41, 225-233.

Bosco A, Rinaldi L, Musella V, Pintus D, Santaniello M, Morgoglione ME, Zacometti G, Cringoli G, 2013. Helminths in Sheep on Farms of the Basilicata Region of Southern Italy. Vet Sci 17, 91-94.

Caminade C, Van Dijk J, Baylis M, Williams D, 2015. Modelling recent and future climatic suitability for fasciolosis transmission risk in Europe. Geospat Health 9, 301-308.

Charlier J, Vercruysse J, Morgan E, van Dijk J, Williams DJ, 2014. Recent advances in the diagnosis, impact on production and prediction of Fasciola hepatica in cattle. Parasitology 141, 326-335.

Cringoli G, Rinaldi L, Maurelli MP, Utzinger J, 2010. FLOTAC: new multivalent techniques for qualitative and quantitative copromicroscopic diagnosis of parasites in animals and humans. Nat Protoc 5, 503-515.

Cringoli G, Rinaldi L, Veneziano V, Capelli G, Malone JB, 2002. A cross-sectional coprological survey of liver flukes in cattle and sheep from an area of the southern Italian Apennines. Vet Parasitol 108, 137-143.

De Roeck E, Van Coillie F, De Wulf R, Soenen K, Charlier J, Vercruysse J, Hantson W, Ducheyne E, Hendrickx G, 2015. Fine-scale mapping of vector habitats using very high resolution satellite imagery: a liver fluke case-study. Geospat Health 8, S671-S683.

Ducheyne E, Charlier J, Vercruysse J, Rinaldi L, Biggeri A, Demeler J, Brandt C, de Waal T, Selemetas N, Höglund J et al., 2015. Modeling the spatial distribution of Fasciola hepatica in dairy cattle in Europe. Geospat Health 9, 261-270.

Duthaler U, Rinaldi L, Maurelli MP, Vargas M, Utzinger J, Cringoli G, Keiser J, 2010. Fasciola hepatica: comparison of the sedimentation and FLOTAC techniques for the detection and quantification of faecal egg counts in rats. Exp Parasitol 126, 161-166.

Fiss L, de Lourdes Adrien M, Marcolongo-Pereira C, Assis-
Brasil ND, Sallis ESV, Riet-Correa F, Ruas JL, Schild AL, 2013. Subacute and acute fasciolosis in sheep in southern Brazil. Parasitol Res 112, 883-887.

Kenyon F, Sargison ND, Skuce PJ, Jackson F, 2009. Sheep helminth parasitic disease in south eastern Scotland arising as a possible consequence of climate change. Vet Parasitol 163, 293-297.

López NV, John BM, Carmona CG, Velásquez LE, 2012. Climate-based risk models for Fasciola hepatica in Colombia. Geospat Health 6, 75-85.

Mas-Coma S, Valero MA, Bargues MD, 2009. Chapter 2. Fasciola, lymnaeids and human fascioliasis, with a global overview on disease transmission, epidemiology, evolutionary genetics, molecular epidemiology and control. Adv Parasitol 69, 41-146.

Mas-Coma S, Valero MA, Bargues MD, 2014. Fascioliasis. Adv Exp Med Biol 766, 77-114.

Morgan ER, Van Dijk J, 2012. Climate and epidemiology of gastrointestinal nematode infection in sheep in Europe. Vet Parasitol 189, 8-14.

Musella V, Catelan D, Rinaldi L, Lagazio C, Cringoli G, Biggeri A, 2011. Covariate selection in multivariate spatial analysis of ovine parasitic infection. Prev Vet Med 99, 69-77.

Musella V, Rinaldi L, Lagazio C, Cringoli G, Biggeri A, Catelan D, 2014. On the use of posterior predictive probabilities and prediction uncertainty to tailor informative sampling for parasitological surveillance in livestock. Vet Parasitol 205, 158-168. Rapsch C, Dahinden T, Heinzmann D, Torgerson PR, Braun U, Deplazes P, Hurni L, Bär H, Knubben-Schweizer G, 2008. An interactive map to assess the potential spread of Lymnaea truncatula and the free-living stages of Fasciola hepatica in Switzerland. Vet Parasitol 154, 242-249.

Rinaldi L, Cringoli G, 2014. Exploring the interface between diagnostics and maps of neglected parasitic diseases. Parasitology 141, 1803-1810.

Skuce PJ, Morgan ER, van Dijk J, Mitchell M, 2013. Animal health aspects of adaptation to climate change: beating the heat and parasites in a warming Europe. Animal 7, 333-345.

Taylor MA, 2012. Emerging parasitic diseases of sheep. Vet Parasitol 189, 2-7.

Van Dijk J, Sargison ND, Kenyon F, Skuce PJ, 2010. Climate change and infectious disease: helminthological challenges to farmed ruminants in temperature regions. Animal 4, 377-392. Yatoo MI, Kumar P, Dimri U, Sharma MC, 2012. Effects of climate change on animal health and diseases. Int J Livest Res 2, $15-24$. 